\title{
Development of Human Machine Interface for the Control of the Integrated Hybridized Renewable Energy Resources in Community-based Power Pool System
}

\author{
${ }^{1}$ Kufre Esenowo Jack \\ Department of Mechatronics Engineering, \\ Federal University of Technology Minna, \\ Niger State, Nigeria
}

${ }^{3}$ Damian Obioma Dike

Department of Electrical / ElectronicsEngineering, Federal University of Technology Owerri, Imo State, Nigeria

\author{
${ }^{5}$ Ubong Akpan Essien \\ Department of Materials and Metallurgical Engineering, \\ Federal University of Technology Minna, \\ Niger State, Nigeria
}

\author{
2 Jude-Kennedy C. Obichere \\ Department of Mechatronics Engineering, \\ Federal University of Technology Owerri, \\ Imo State, Nigeria
}

\author{
${ }^{4}$ Matthew Olubiwe \\ Department of Electrical / Electronics Engineering, \\ Federal University of Technology Owerri, \\ Imo State, Nigeria \\ ${ }^{6}$ Justice Chikezie Anunuso \\ Department of Mechatronics Engineering, \\ Federal University of Technology Minna, \\ Minna State, Nigeria
}

\section{INTRODUCTION}

Abstract - Renewable energy resources are those energy resources that are naturally provided by nature solely for the purpose of generating energy. The source of these renewable resources includes sun light, wind, rain, tides and geothermal heat. This design uses PLC in controlling and SCADA in Monitoring the system behaviors. The PLC in-use is Keyence and the SCADA inuse are in touch. The design provides a touch screen Human Machine interface that helps all the pool resources to be centrally managed thus, eliminating energy wastage. With this, all the pool agents with their respective energy generated are put to use. Five different communities were selected for this prototype experimentation. The results revealed that the Operators and Machine were synchronously interacted for the optimum energy utilization. The contribution to knowledge in this research work are enumerated and it reveals that it is feasible to achieve the interconnection of the community-based hybridized system together with the available renewable energy resources within the Afikpo metropolis for Power Pooling Purpose; uncovered the possibility of monitoring and controlling of the power pool system with the aids of the PC touch screen HMI implementable using PLC and SCADA configuration and developed a model for the determination of the hybridized power pool system. The research work was $90 \%$ achieved through simulation. Further research work should be tailored towards developing a similar scheme to cover five local government areas for upward eradication of energy wastages.

Keyword-Human Machine Interface (HMI), Power Pool System, Hybridization, Control and Supervisory Control \& Data Acquisition (SCADA)
Renewable energy resources are those energy resources that are naturally provided by nature solely for the purpose of generating and regenerating energy for continuous usages [1]. The source of these renewable resources includes sun light, wind, rain, tides and geothermal

heat [2]. Renewable Energy Resources are free and replaceable.

Human Machine Interface uses computer systems as an interface between utility operations staff and SCADA system, the Programmable Logic Controller (PLC) are specialized industrial computer control systems that are design to continuously monitor the state of input devices and makes decisions based upon a custom program to control the state of output devices[3]. Supervisory Control and Data Acquisition (SCADA) is a term that refers to an entire industrial control system that consists of instrumentation, communications.

PLC automation equipment, and human machine interface (HMI) computer systems. Tag is a name within a SCADA database that uniquely defines data used by the SCADA system. A tag has a number of attributes that, together, completely define the tag. Human Machine interface help in providing sufficient level of details which enable the operator to determine what is happening in the system and what is going to happen next (Process sequence). Graphical interface provide 
access to parameters for tuning and provides the seasonal information that is required to be built into the system.

The renewable energy resources (RER) are considered to be an alternative to other energy generating systems in view of its hydrocarbon-based deficiencies which has been proven to be unfriendly with the environment. Its availability varies from a particular geographical zone to another. Some renewable energy resources such as solar, hydropower and wind are climate dependent. To sufficiently harvest the electrical energy generated from these renewable energy resources, there is priority attention on optimization design scheme considering the plight of the urban dwellers [4]. RERs are clean and environmentally friendly, the distribution of the generated energy is allowed because of its high level of generated power. Since its performance varies depending on the geographical zone, the combination of two or more renewable energy resources has become imperative in that when one geographical zone is facing energy outage, energy from another geographical zone will help in compensating that zone. Secondly, this system can generally improve the resultant power in the communities involved by integrating all the energy generated in the combined system. Thirdly, with this system, the community with excess energy does not waste it, as it can easily be channeled to another community with insufficient energy. This concept is termed energy pool.

Energy pool can be a combination of many hybridized energy systems. A hybridized energy system has to do with different energy sources combined together to generate energy. This arrangement ultimately depends on the available natural resources within the community. As a result, a community with abundant water bodies with high current and wind can have a hybridized hydro and wind system. This system would be managed by its own administrator. Similarly, another community could be rich in sun and wind and so establish a solar and wind hybridized system, with its own administrator. All these hybridized systems could be linked together to form an energy pool system with only one central administrator.

With this pool in place, there would be a considerable guarantee of energy balance among all the communities involved. This is more especially as the natural resources are highly variable. It is therefore possible that the intensity of sun can decrease drastically from one community to another with a hybridized solar and wind system thereby reducing the resultant energy generated from that community. The pool system guarantees energy compensation from another community with sufficient energy at that time to still serve the general system. This same compensation also happens in terms of outright power failure from a particular community. By so doing, there would be energy balance in all the communities under study.

Despite the hybridization of the renewable systems, effective and reliable operation is required and this will involve the selection of components or parameters that will manage the inherent weakness or inconsistency of any of these renewable systems as designed [5]. It is important for communities not to see their available renewable energy resources as being ultimate and standalone resource rather a community-global energy system that can be put together for higher efficiency, effectiveness, reliability and sustainability. The interconnections of all the community-based renewable system for resources from energy generated from different geographical areas are termed power pool system [6]. This harmonized arrangement between different geographical areas on energy matters was researched upon and implemented on a larger grid [7]. With this arrangement, locally generated electricity will form a micro-grid for communities to interchange their products and significantly, the energy demand for certain communities will thus be met. Power pooling requires further optimization system for effective utilization of energy in the rural/urban communities. With this harvested RERs more technologies for energy storage, conversion and load demand management system (economic dispatch) are needed as its transportation from one location to another will result in some losses [8]. Optimal design and planning have become an important aspect of the renewable energy resources because of its combinational capabilities and potentials within its co-resources for minimal cost of energy supply and maximum reliability. RERs are far more useful beyond the alternative projection. It has now been residentially utilized considering its economic and reliability advantages. This is also a good step in solving the rural ill-energy system problem [9]. The integration of renewable energy resources like wind, solar, hydro, biomass with other energy system will enable sustainable development in community-based energy supply. Hence, the necessitation for the RERs control to prove its general acceptance in the energy sustainability is the thrust of this study.

\section{OBJECTIVES}

The world is drastically shifting to more efficient, effective, reliable and environmentally friendly energy sources like the wind, solar, biomass and hydro energy system. These renewable energy resources are dynamic in nature; they are environmentally dependent and therefore require efficient management monitoring and control system. Some communities have comparative advantage of potential energy sources than others and for these reasons, there is need for collaborative power pooling scheme for stable and sustainable energy supply. The Power pool system required Human Machine Control Interface for its visual data display, track of the production time, trends, and tags and Monitoring of each pool inputs as well as the general pool outputs level. The inability for communities to rise up to the challenges of non-supply of electrical energy in their dwelling places has led to a potential neglect of the natural renewable energy resources and even the few available renewable energy resources require an optimal system configuration. [10] elucidate that for rural electrification to be a success, attention should be given to community energy production increment and on-site energy generating systems. These will foster large quantity of energy with the concept of pooling system. Similarly, some bottlenecks encountered in the renewable energy system include: high initial or takeoff cost; low conversion efficiency which this research intends to optimize; skilled manpower not readily available at the community level, in which this research will demonstrate an easy operational concept to fill the rural needs. The world is facing challenges in energy security, sustainability and pollution as a result of hydrocarbon, which leads to climate changes. Therefore, the advent of Renewable Energy Resources will ensure 99\% if not $100 \%$ 
reduction in the aforementioned challenges [11]. Objectively, a Screen touched HMI for the Control of the Power Pool System was designed, a remote access means of monitoring the community-based Renewable Resource use for the Power Pool System in a view of tracking their production time, trends and targets was designed suitable data injection model to represents their respective generated energy under a hybridized scenario; and simulation of the designed work was done for validation and analysis t of he results.

\section{LITERATURE REVIEWED}

\section{Stand Alone Solar System}

Abhaya Swarup et al [12] proposed a developed model for energy management of PV based energy system. This model has been mainly proposed to raise the public awareness and education levels of solar systems in an interesting and entertaining way. The results indicate that the problems with PV systems were not due to PV array and instead it was due to the performance of the battery units.

Martina et al [13] have discussed about multilevel converters that are effectively used to connect single- phase grid with solar photovoltaic systems. An overview of different multi-level topologies and the suitability for single-phase grid connected photovoltaic systems has also been presented.

Vivek Kapil et al [14] have developed an Artificial Neural Network (ANN) model for designing PV systems for remote areas and presented the influence of various parameters on the design of PV systems. The results of ANN model showed a variation of $5 \%$ as compared to other models with more reliability and accuracy. The application of solar power is varied and the scope of PV systems being employed even in domestic applications appears to be bright.

Mohanlal Kolhe et al [15] analyzed the economic viability of a standalone solar photovoltaic system with the most likely conventional alternative system i.e. a diesel-powered system for energy demand through sensitivity analysis of life cycle cost computation. The analysis has been carried out for the energy demand for different key parameters, such as discount rate, diesel fuel cost, diesel system lifetime, fuel escalation rate, solar isolation, PV array cost and reliability. The result showed that the PV powered systems could be a cost-effective option at a daily energy demand up to $15 \mathrm{kWh}$ even under unfavorable economic conditions.

\section{Standalone Wind Systems}

AydoganOzdamar et al [16] analyzed and presented a case study on wind energy utilization in a house in Izmir, Turkey. The developed model determines the number of batteries needed for continuous energy supply, for each wind turbine taking into account of the economic aspects. It was found that the wind battery hybrid system was not economical in the areas of low wind potential.

Kanat A. Baigarin et al [17] have discussed about the potential of wind energy resources available in central Asia. The equations used for determining the distribution of wind energy output, energy density, energy cost and efficiency have been discussed in detail.

Suresh H. et al [18] have developed a model to investigate the optimum sitting of wind turbine generators based on site and wind turbine type. The methodology of analysis was based on the accurate assessment of wind power potential of various sites. The analytical computation of annual and monthly capacity factors has been carried out by using the waybill statistical model employing cubic mean cube root of wind speeds. A judicious choice of potential sites and wind turbine generator systems can be made using the model proposed.

\section{Solar Photovoltaic Wind Hybrid System}

Bhave A.G [19] studied the techno-economic feasibility of installing solar photovoltaic-wind hybrid system. This system uses electrical storage by lead acid battery and auxiliary power from AC mains. The result from the above study showed that $80 \%$ of the energy demand was satisfied by the solar photovoltaic wind hybrid system. But it was cost effective, only when the system cost was considerably reduced or the current electricity cost raised to a much higher level.

Francois Giraud et al [20] analyzed a model for design of windphotovoltaic system with battery storage for grid connected rooftop system. The system was designed to meet a typical load demand for a given loss of power supply probability. The various parameters like system reliability, power quality, loss of supply and effects of the randomness of the wind and the solar radiation on systems design have been studied. The results showed that the wind and solar systems were complementary to each other and resulted in improved reliability of the system.

Rajesh Karki [21] developed a simulation method for photovoltaic and wind energy utilization in small isolated power systems based on reliability/cost implications. This simulation method provides objective indicators to help system planners decide upon appropriate installation sites, operating polices selection of energy types, sizes and mixes in capability expansion. In this model, cost and reliability are the main parameters to be considered as it has a significant impact on the design.

\section{MATERIALS AND METHOD MATERIALS}

The following software-based tools or components were used to achieve this project.

i. PLC: Keyence KV24

ii. SCADA: Wonder ware in touch

iii. HOMER

\section{A Methods}

The methods to be used in designing each of the components of the system are represented in Fig. 1. 


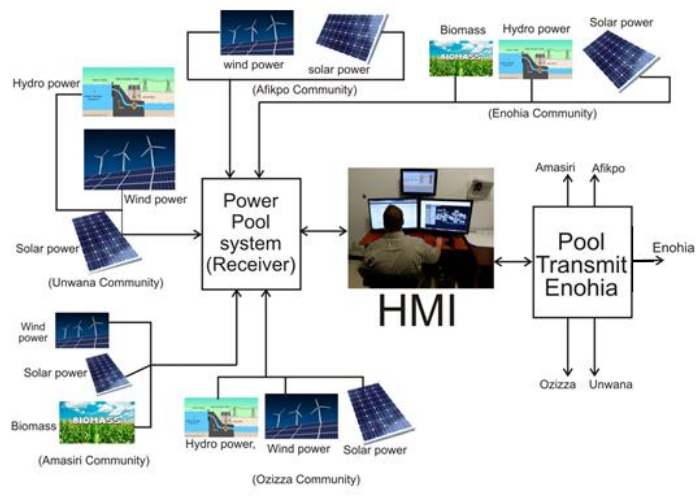

Figure 1: Block diagram of the human Machine interface for the Control of Hybridized Community-based Power Pool System.

The total amount of energy supplied to the Afikpo North local Government area from Enugu Electricity Distribution Company is $8 \mathrm{MW}$ at peak. 10 Megawatt of energy is expected to be generated into the micro grid system for the five communities to utilize experimentally. These are the expectation from each of the renewable resource to make up to the required $10 \mathrm{MW}$.

i. Solar is expected to generate about $3 \mathrm{MW}$

ii. Biomass is expected to generate about $2 \mathrm{MW}$

iii. Hydro is expected to generate about $2 \mathrm{MW}$

iv. Wind is expected to generate about $3 \mathrm{MW}$

$B \quad$ Design of screen Touched HMI for the Control of the Power Pool System

\section{Background Details of Wonderware intouch software use in SCADA design}

InTouch software has the Human Machine Interface; this is used in the Visualization for the Manufacturing ventures. The Human Machine Interface (HMI) software application gives the graphical representation of a manufacturing and processing environment. It uses tools, materials, and processes in creating product appearance as visual elements in the Human Machine Interface in the application windows. This is where the Plant operators and the field devices interactions and applications are graphically monitored as the control actions are administered in the processes.

C The reason for adopting the in-touch software is as follows:

i. It helps in a remote monitoring

ii. It facilitatesself-fault diagnosing with ease

iii. It has a database documentary for the field operation

iv. It has the ability to keep the history of operation

v. It transfers thePLC programcode through input/output drives

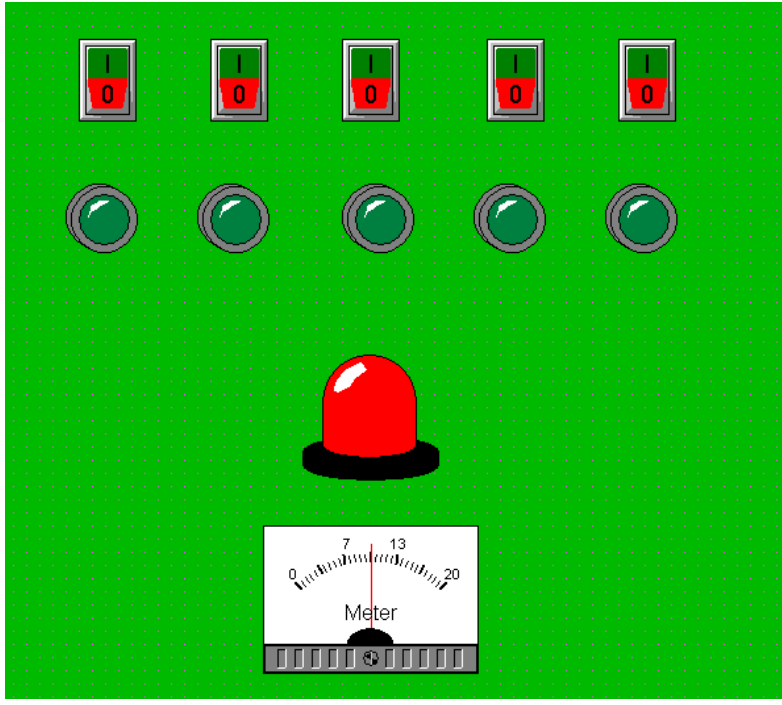

Figure 2: The Human machine interface

$D \quad$ Design of a Remote access means of monitoring the community-based renewable resources used for the power pool system in a view for tracking their production time, scripts, trends and target

The software simulation tools and step in developing a (SCADA) system

i. Creating New application and windows

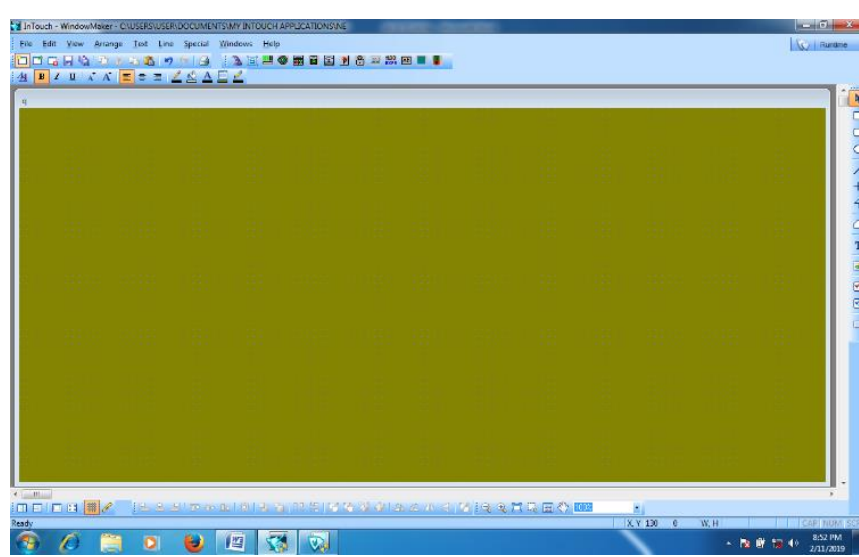

Figure 3: Newly Created application and windows

ii. Tag definition

a) ta is the tag name for Afikpo power line

b) $\mathrm{cc}$ is the tag name for Amasiri power line

c) dd is the tag name for Enohia power line

d) ee is the tag name for Ozizza power line

e) ff is the tag name for Unwana power line

f) bb is the tag name for integrated power bus system

g) oo is the tag name for metering device

iii. Objects selection, placement and Animation design

iv. Writing script

v. Select run time and toggle the switch device

vi. Real time trends and Historical trends

vii. Design of the Alarms and trip System 


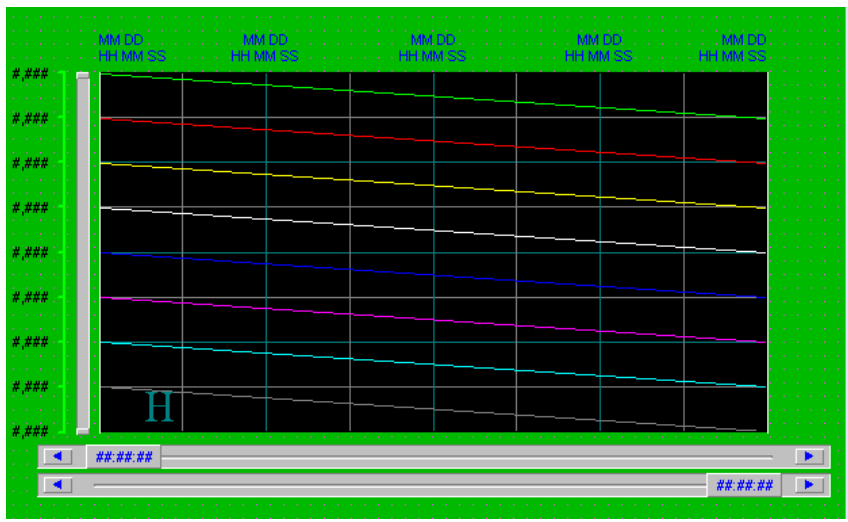

Figure 4: The design trend Historicaltrends

A fully automated system requires safety instrumented system. The alarm is design primarily to alert the operator of the system malfunctioning and the trip is design to isolate the system under these fault condition where alarm has rang for three minute without the operators attention and shut down emergently.

\section{$E$ Designof suitable data injection Model to represents their respective generated energy under a hybridized scenario}

To achieve this, HOMER Software is used as a model for the system based on the data adapted from already optimized hybridized systems corresponding to the information of the National Population Commission on Afikpo North demographic survey Population data.These are used to determine as an assumed energy requirement for the communities under investigation. To achieve this task, the following steps will be taken; one of the specific tasks in this project is to develop a hybridized power system injection model commensurable with the energy demand of the community understudy:

\section{$F \quad$ Simulation of the Design for Validation}

The Basic Development of a (PLC) Program and the Predesign logic gate concept to satisfy the design theorem

\section{Logic Gate}

\section{OR Gate}

Logic Symbol

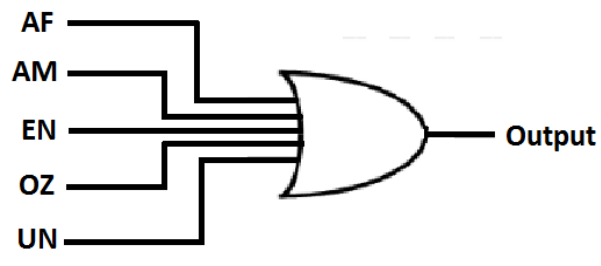

Figure 5: The Logic configuration of the OR gate

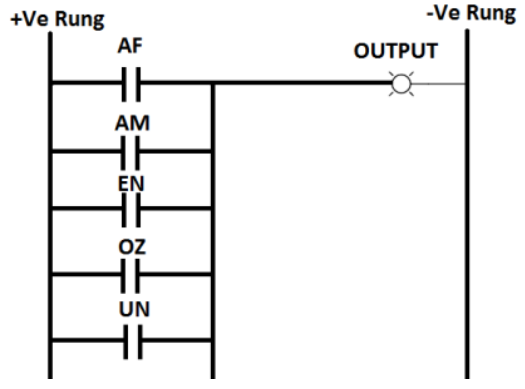

Figure 6: The Ladder diagram of the OR gate

The Electrical equivalent of the OR gate

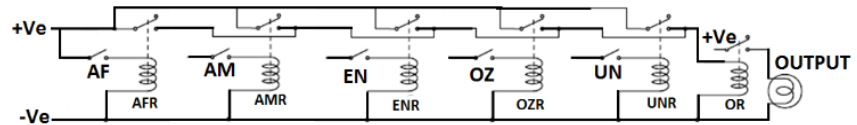

Figure 7:The Electrical equivalent diagram of an OR Gate

This represent the logic composition of the gate agorthim the five communities unstudy.

Table 1: Logic gate Composition

\begin{tabular}{|c|c|c|c|c|c|c|}
\hline & & \multicolumn{4}{|c|}{ OR Gate Analogy with 5 Input } & \multirow[b]{2}{*}{$\begin{array}{l}\text { Power } \\
\text { Outpu }\end{array}$} \\
\hline & $\begin{array}{l}\text { Afikpo } \\
\text { (AF) }\end{array}$ & $\begin{array}{l}\text { Amaziri } \\
\text { (AM) }\end{array}$ & $\begin{array}{l}\text { Enobia } \\
\text { (EN) }\end{array}$ & $\begin{array}{l}\text { Qzzia } \\
\text { (OZ) }\end{array}$ & $\begin{array}{l}\text { Unwana } \\
\text { (UN) }\end{array}$ & \\
\hline 0 & 0 & 0 & 0 & 0 & 0 & 0 \\
\hline 1 & 0 & 0 & 0 & 0 & 1 & 1 \\
\hline 2 & 0 & 0 & 0 & 1 & 0 & 1 \\
\hline 3 & 0 & 0 & 0 & 1 & 1 & 1 \\
\hline 4 & 0 & 0 & 1 & 0 & 0 & 1 \\
\hline 5 & $\circ$ & 0 & 1 & 0 & 1 & 1 \\
\hline 6 & 0 & 0 & 1 & 1 & 0 & 1 \\
\hline 7 & 0 & 0 & 1 & 1 & 1 & 1 \\
\hline 8 & 0 & 1 & 0 & 0 & 0 & 1 \\
\hline 9 & 0 & 1 & 0 & 0 & 1 & 1 \\
\hline 10 & 0 & 1 & 0 & 1 & 0 & 1 \\
\hline 11 & 0 & 1 & 0 & 1 & 1 & 1 \\
\hline 12 & 0 & 1 & 1 & 0 & 0 & 1 \\
\hline 13 & 0 & 1 & 1 & 0 & 1 & 1 \\
\hline 14 & 0 & 1 & 1 & 1 & 0 & 1 \\
\hline 15 & 0 & 1 & 1 & 1 & 1 & 1 \\
\hline 16 & 1 & 0 & 0 & 0 & 0 & 1 \\
\hline 17 & 1 & 0 & 0 & 0 & 1 & 1 \\
\hline 18 & 1 & 0 & 0 & 1 & 0 & 1 \\
\hline 19 & 1 & 0 & 0 & 1 & 1 & 1 \\
\hline 20 & 1 & 0 & 1 & 0 & 0 & 1 \\
\hline 21 & 1 & 0 & 1 & 0 & 1 & 1 \\
\hline 22 & 1 & 0 & 1 & 1 & 0 & 1 \\
\hline 23 & 1 & 0 & 1 & 1 & 1 & 1 \\
\hline 24 & 1 & 1 & 0 & 0 & 0 & 1 \\
\hline 25 & 1 & 1 & 0 & 0 & 1 & 1 \\
\hline 26 & 1 & 1 & 0 & 1 & 0 & 1 \\
\hline 27 & 1 & 1 & 0 & 1 & 1 & 1 \\
\hline 28 & 1 & 1 & 1 & 0 & 0 & 1 \\
\hline 29 & 1 & 1 & 1 & 0 & 1 & 1 \\
\hline 30 & 1 & 1 & 1 & 1 & 0 & 1 \\
\hline 31 & 1 & 1 & 1 & 1 & 1 & 1 \\
\hline
\end{tabular}

$G \quad$ Procedural appoach in deveolping PLC Control Program with Kenyence PLC

i. $\quad$ Latching

In this design latching concept allows for the status of the output to remain $\mathrm{ON}$ and hold it up. 
[1] LADDER BUILDER [Simulator:KV24] - LDW_1.LDR - [Ladder Monitor]

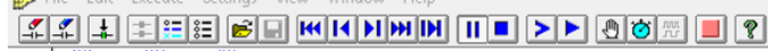<smiles>CC1(C)C[C@@H]2[C@@H](O)C[C@H]21</smiles>

ii. Memory

Figure 8: Design latching

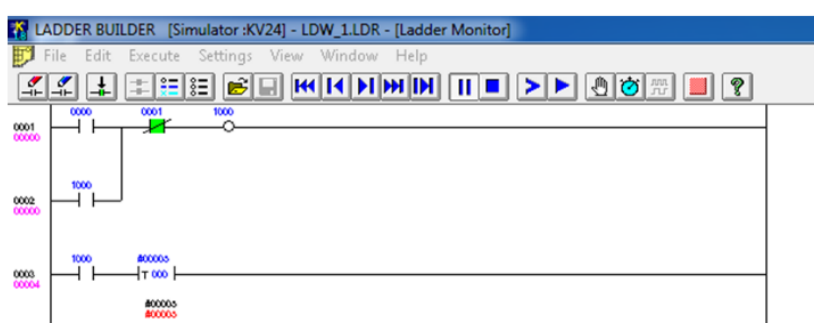

Figure 9: Design memory

iii. Write the Program

iv. END

v. ENDH

vi. Compile

vii. Simulate

viii. Execute: one step, continuously step or high speed

\section{$H \quad$ The Development of a (PLC) Program for Enohia Line}

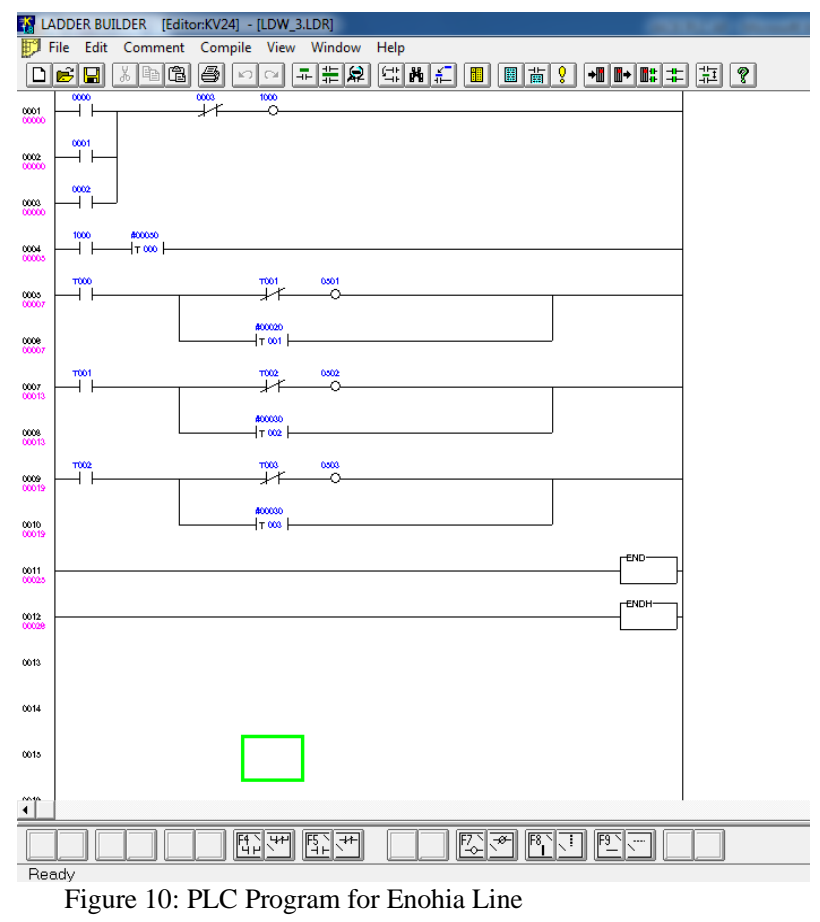

\section{$J$}

\section{The Development of a (PLC) Program for Afikpo Line}

19ADDER BUILDER [Simulator:KV24] - LDW_2.LDR

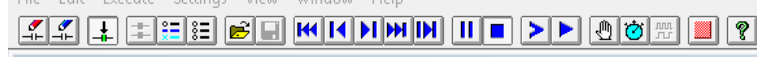

\section{䛗 Ladder Monitor}

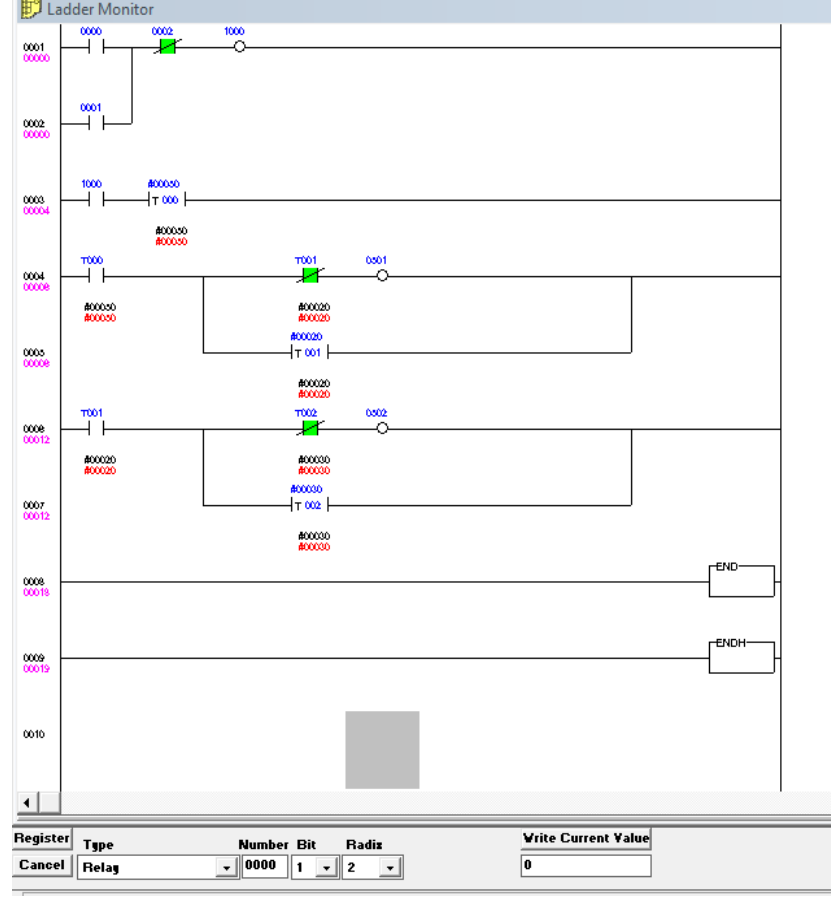

Figure 11: PLC Program for Afikpo Line

\section{The Development of a (PLC) Program for} Amasiri Line

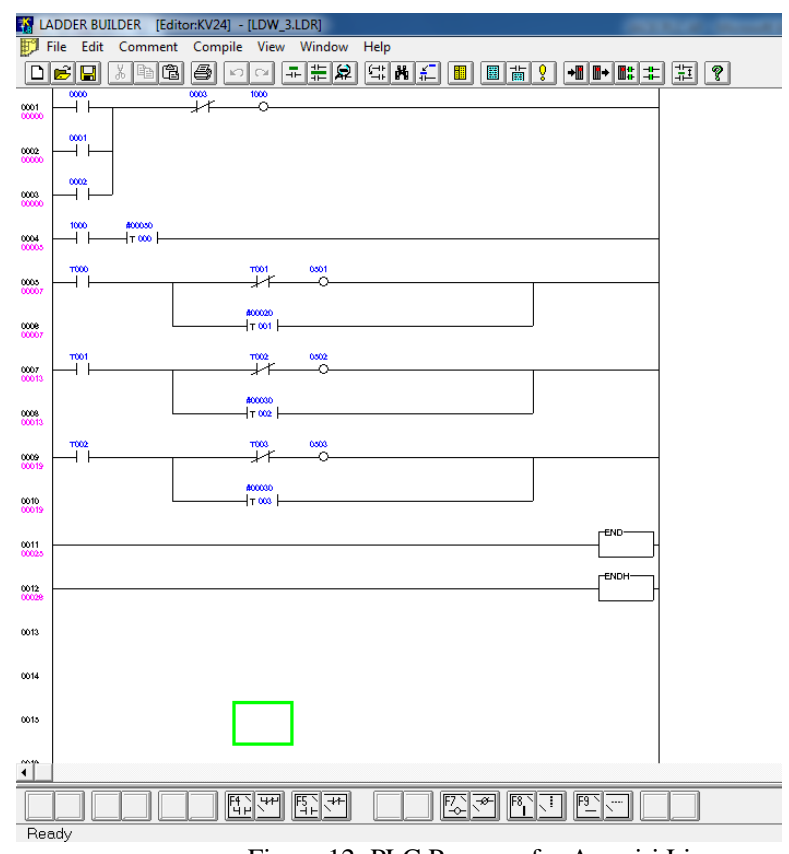

Figure 12: PLC Program for Amasiri Line 


\section{K \\ The Development of a (PLC) Program for Ozzia} Line

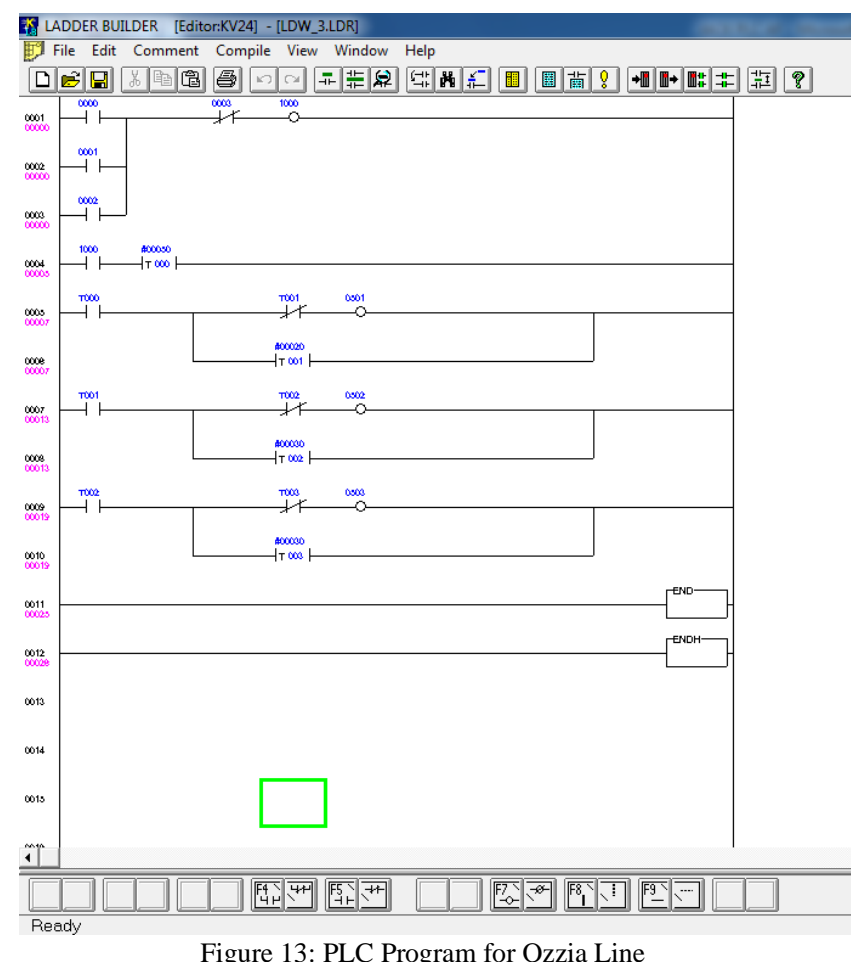

Figure 13: PLC Program for Ozzia Line

\section{$L \quad$ The Development of a (PLC) Program for Unwana Line}

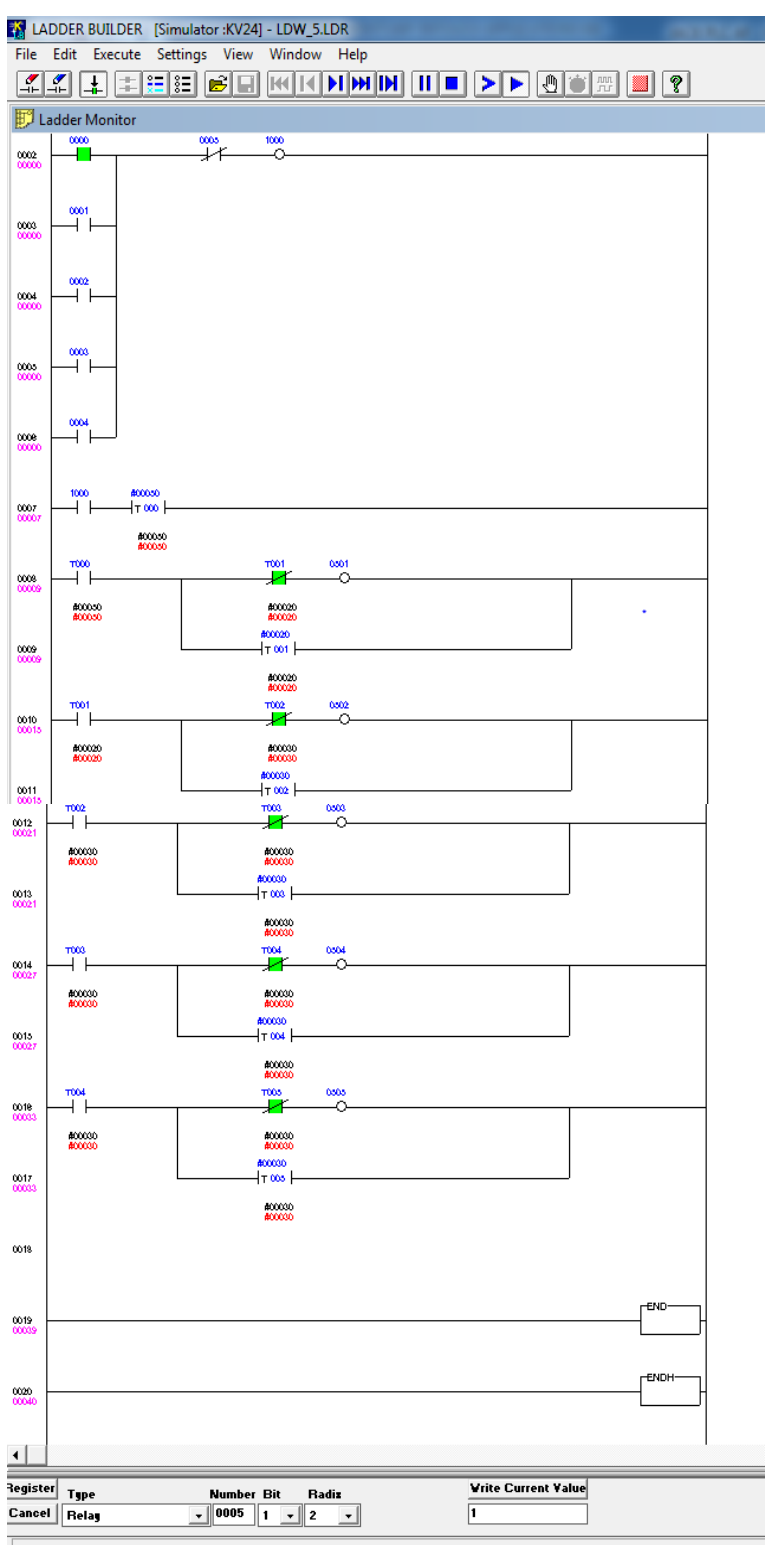

Figure 14: PLC Program for Unwana Line 


\section{$M$ The Development of a Central (PLC) Control} Program for the five communities under study

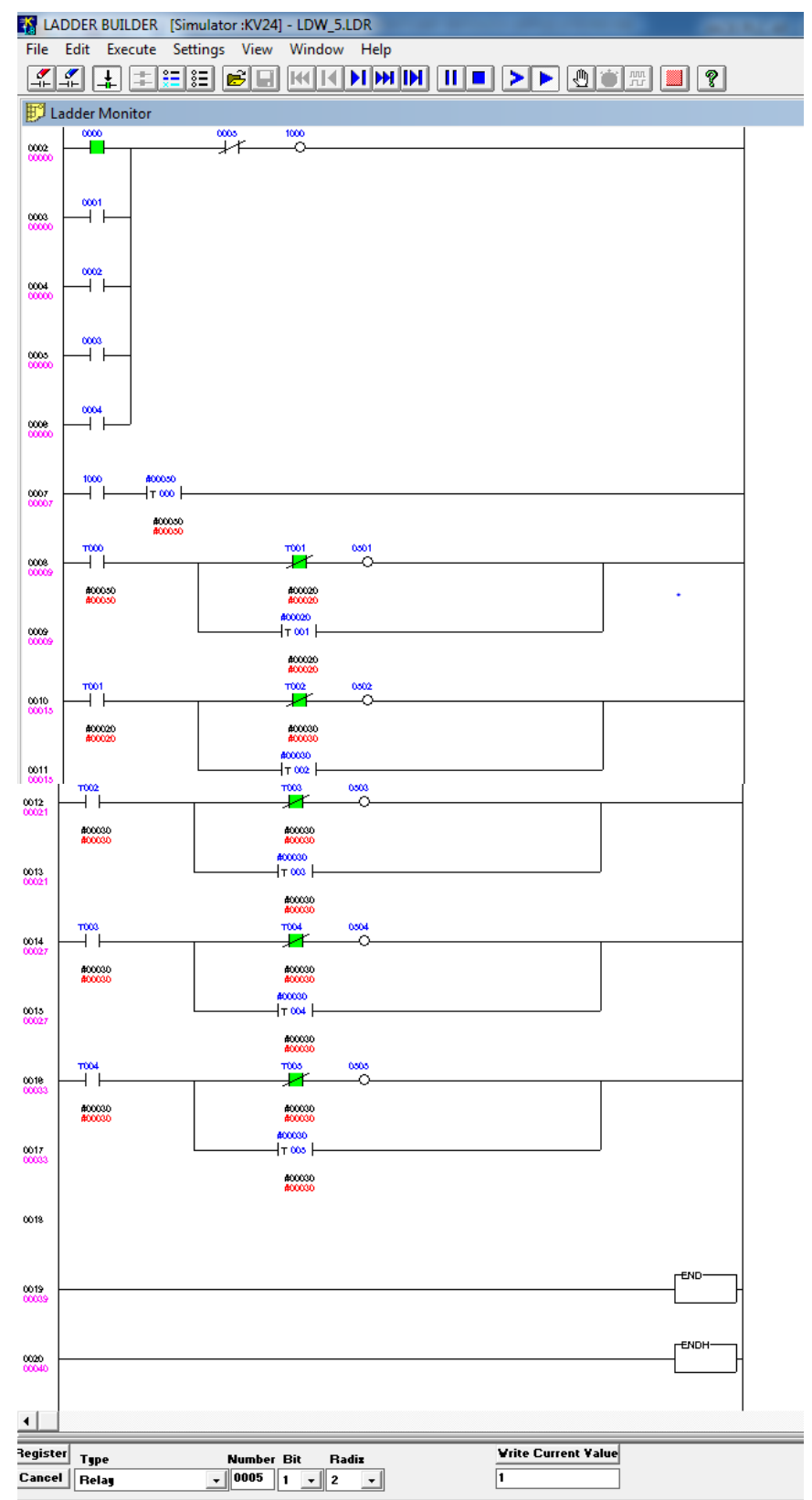

Figure 15: PLC Program for the control of Five Communities under study
$N$

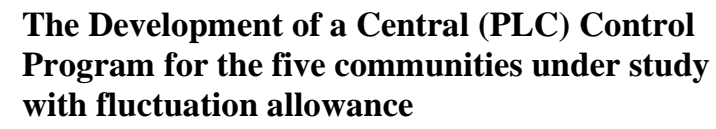

The Development of a Central (PLC) Control Program for the five communities under study with fluctuation allowance

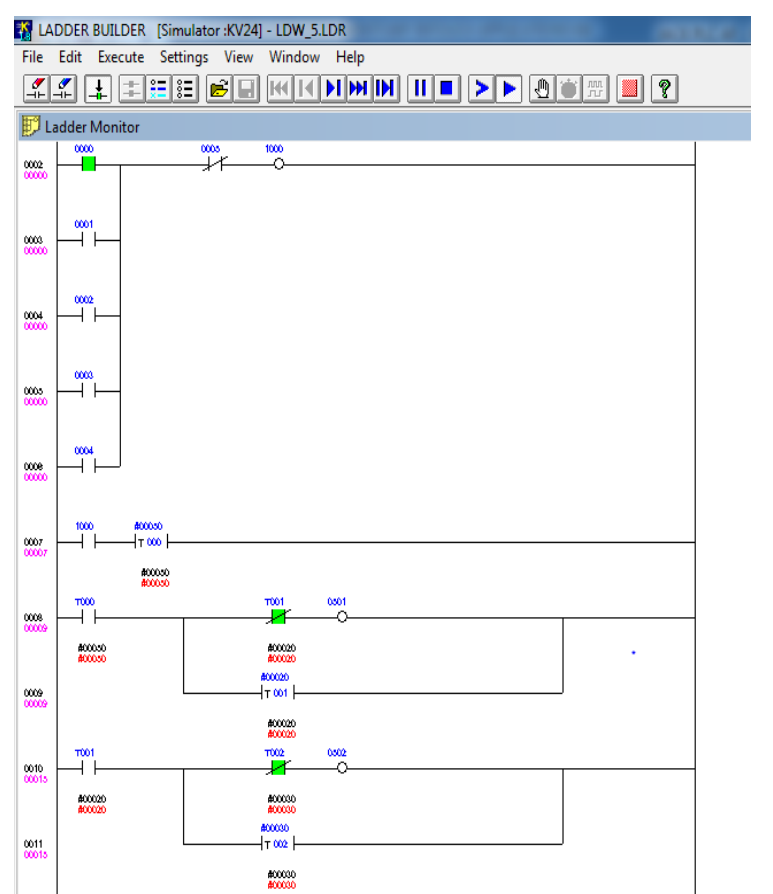

Figure 16: PLC Program for the control of Five Communities under study with fluctuation allowance

\section{$O \quad$ Summary of Materials and Methods}

The PLC software design was achieved using Keyence PLC with builder KV24.This design aids the switching and control of the five renewable energy resources from the communities under experimentation through its ladder program. Synchronization of the energy generated from each source to the mid-grid was possible through its program code.

The SCADA software design was also achieved using Wonderwareintouch 9.0. This created the virtual object which aids in monitoring of the field operation from each of the energy sources, through its scripts program which uses $\mathrm{C}$ language. For the possible interaction between the PLC \& SCADA, i/o drivers are employed whereas in the real-life situation Remote Terminal Unit (RTU) are used.

However, HOMER software wereexplored to give the hybridized and optimized design leading to energy unit use by each community under study

\section{RESULT AND DISCUSSION}

\section{Presentation of Results Introduction}

The Renewable Energy Resources and its energy potentials within Afkpo Metropolis have been analyzed. Electricity generated from the renewable energy resources of Wind, Biomass, Solar and Hydro was hybridized for communitybased use. The Power Pool system monitoring and control of Human Machine interface has been developed using PLC \& SCADA. Various control and monitoring constituents of the energy resources which were considered a necessity for the power pool system operation are presented (Software and virtual Graphic). These enable the system to provide reliable and efficient energy control. These also allows for a rising 
energy demand future management. The results obtained from this experimentation as simulated and analyzed are discussed in the following sections.

\section{A Result and Discussion on the Design of a Screen} Touched Human MachineInterface (HMI) for the Control of the Power Pool System

The screen touched Human Machine Interface design uses the following tools to actualize the system. The panels, frames, switches, relay, push button, lights, meters and factory symbols. The panels and frames form the design background for the developed system. The switches, push button and relay are design switch ON/OFF of the energy generated from Afikpo, Amasiri, Enohia, Ozzia and Unwana line respectively. The metering devices shows individual energy pool used from each contributor in terms of voltages, current and power as they are synchronized into the bus, according to the script program(c-language). As the PLC ladder program is energized by the operator, switch 1 which is the Afikpo line controller is energized after $10 \mathrm{sec}$, the Amasiri line is energized up till the last Unwana line. In each of the activities, HMI Screen displays the action for the operator to see. In case of any unit malfunctioning there will be an alarm alert but after $5 \mathrm{sec}$ if the operator pays no attention to the system behavior, the system will automatically initiate an emergency shutdown action. When each of the energy sources connects to the pool system generated voltage and indicates in the metering system.

$B \quad$ Result and discussion on the design of a Remote access means of monitoring the community-based renewable resources.

The remote access is facilitated by the RUT or i/o drivers. These mediate between the PLC program and the SCADAscript program. As the operation is going on, data are presented in the real and historical trend.

Result and Discussion on the Design of Suitable
Data Injection Model to Represents their
Respective Generated Energy Under a
Hybridized Scenario,

Hybrid System Design Result and Discussion

\section{HYBRID SYSTEM DESIGN FOR AFIKPO COMMUNITY WITH SOLAR AND WIND ENERGY POTENTIALS.}

The result reveals that the solar and the wind configuration generated $5 \mathrm{KV}$ for the resources available in Afpko community.

Hybrid System design for Amasiri Community with Biomass, Solar and Wind Energy Potentials.

The result reveals that the Biomass, solar and the wind configuration generated $5 \mathrm{KV}$ for the resources available in Amasiri Community.
$B$

Hybrid System design for EnohiaCommunity with hydro, Solar and biomass Energy Potentials.

The result reveals that the solar and the wind configuration generated $5 \mathrm{KV}$ for the resources available inEnohia Community

\section{Hybrid System design for Ozzia Community with hydro, Solar and Wind Energy Potentials.}

The result reveals that the Biomass, solar and the wind configuration generated $5 \mathrm{KV}$ for the resources available inOzzia Community

D Hybrid System design for Unwana Community with Biomass, Solar and Wind Energy Potentials.

The result reveals that the Biomass, solar and the wind configuration generated $5 \mathrm{KV}$ for the resources available inUnwana Community

All the $5 \mathrm{KV}$ s was later step up with PT to $11 \mathrm{KV}$ Bus from use.

\section{RESULT AND DISCUSSION ON THE VIRTUALLY RUNNING OR SIMULATION OF THE DESIGN FOR VALIDATION}

\section{The PLC System Design Result and Discussion}

\section{A Afikpo Line Result and Discussion}

The Afikpo community has the Solar and Wind potentials. The wind and solar were designed as a standalone system at the initial stage but integrated to a hybrid system through a bus. Firstly, the solar resources were integrated into the bus after 10 seconds then a wind resource was integrated as in Figure11.

\section{$B \quad$ Amasiri Line Result and Discussion}

The Amasiri community has the Biomass, Solar and Wind potentials. The wind, Biomass and solar were designed as a standalone system at the initial stage but were integrated to a hybrid system through a bus. These renewable energy resources follow the sequence of operation for their integrated. The solar, Biomass and wind resources were integrated into the bus after 10 seconds sequentially as in Figure 12.

\section{Enohia Line Result and Discussion}

The Enohia community has the Biomass, Solar and Hydro potentials. The Hydro, Biomass and solar were designed as a standalone system at the initial stage but were integrated to a hybrid system through a bus. These renewable energy resources follow the sequence of operation for their integrated. The solar, Biomass and Hydro resources were integrated into the bus after 10 seconds sequentially as in Figure 10.

\section{Ozzia Line Result and Discussion}

The Ozzia community has the Biomass, Solar and Hydro potentials. The Hydro, Wind and solar were designed as a standalone system at the initial stage but were integrated to a hybrid system through a bus. These renewable energy resources follow the sequence of operation for their integrated. The Solar, Wind and Hydro resources were integrated into the bus after 10 seconds sequentially as in Figure 13. 


\section{E Unwana Line Result and Discussion}

The Unwana community has the Biomass, Solar and Hydro potentials. The Biomass, Wind and solar were designed as a standalone system at the initial stage but were integrated to a hybrid system through a bus. These renewable energy resources follow the sequence of operation for their integrated. The Solar, Wind and Biomass resources were integrated into the bus after 10 seconds sequentially as in Figure 14.

\section{RESULT AND DISCUSSION FOR THE FIVE INTERCONNECTED COMMUNITIES WITH PLC}

Figure 15 shows the central control design for the five communities, from the design Algorithm; the initial/ home conditions were set with Afikpo power line (I/P), Amasiri power line (I/P), Enohia power line (I/P) Ozzia power Line $(\mathrm{I} / \mathrm{P})$ and Unwana power line $(\mathrm{I} / \mathrm{P})$ are labeled as Input 0000 , $0001,0002,0003,0004$ and 0005 respectively. The five Outputs Afikpo power line $(\mathrm{O} / \mathrm{P})$, Amasiri power line $(\mathrm{O} / \mathrm{P})$, Enohia power line $(\mathrm{O} / \mathrm{P})$, Ozzia power Line $(\mathrm{O} / \mathrm{P})$ and Unwana power line (O/P) are labeled as Output 0500, 0501, 0502, 0503, 0504 and 0505 respectively. The 1000 is the memory address which enables the latching operation. The latching involves the act of retaining the power of the system when the input power has been removed in rung 0 . The algorithm steps involved in switching the generated power from each of the five communities to the ON state is summarized as follows:

STEP 1: 0000,0001,0002, 0003 and 0004 then 0500, 0501, 0502, 0503 and 0504, the system remainsin OFF state but if any of the input is $\mathrm{ON}$, those output will be energized one after the other using the timer instruction.

STEP 2:1000 as latched triggers the timer T000 comes ON after 50 seconds for the Afikpo power line (0500) to be loaded after synchronization into the micro-grid system. But the normally close contact (T001) will enable only the Afikpo power line alone to be loaded at that particular time.

STEP 3: The timer address T001 become latched thereby energizing the T002 to become ON after 20 seconds for the Amaziri power line (T002) will be loaded after synchronization into the micro-grid system. But the normally close contact (T002) will enable only the Amaziri power line alone to be loaded at that particular time.

STEP 4:The timer address T002 become latched thereby energizing the T003 to become ON after 10 seconds for the Enohia power line (T003) will be loaded after synchronization into the micro-grid system. But the normally close contact (T006) will enable only the Enohiai power line alone to be loaded at that particular time.

STEP 5: The timer address T003 become latched thereby energizing the T004 to become ON after 10 seconds for the Ozzia power line (T004) will be loaded after synchronization into the micro-grid system bus. But the normally close contact (T004) will enable only the Ozzia power line alone to be loaded at that particular time.

STEP 6: The timer address T004 become latched thereby energizing the T005 to become ON after 10 seconds for the Uwnana power line (0505) will be loaded after synchronization into the micro-grid system. But the normally close contact (T005) will enable only the Unwana power line alone to be loaded at that particular time. All these actions will be monitoring from the human machine interface and if it requires any alteration, the operator can affect it. If the entire operation is to be put on hold, the normally closed contact (T005) will be reenergized by the operator.

\section{RESULT AND DISCUSSION FOR THE FIVE INTERCONNECTED COMMUNITIES WITH PLC PROGRAM TO CONTROL ENERGY FLUCTUATION}

Figure 16 shows the central control design for the five communities, from the design Algorithm; the initial/ home conditions were set with Afikpo power line (I/P), Amaziri power line (I/P), Enohia power line (I/P) Ozzia power Line (I/P) and Unwana power line (I/P) are labeled as Input 0000 , $0001,00020003,0004$ and 0005 respectively. The five

Outputs Afikpo power line $(\mathrm{O} / \mathrm{P})$, Amaziri power line $(\mathrm{O} / \mathrm{P})$, Enohia power line $(\mathrm{O} / \mathrm{P})$, Ozzia power Line $(\mathrm{O} / \mathrm{P})$ and Unwana power line $(\mathrm{O} / \mathrm{P})$ are labeled as Output 0500, 0501, 0502 0503, 0504 and 0505 respectively. The 1000 is the memory address which enables the latching operation. The latching involves the act of retaining the power of the system when the input power has been removed in rung 0 . The algorithm steps involved in switching the generated power from each of the five communities to the ON state is summarized as follows:

STEP 1: 0000,0001, 0002 0003, 0004 and0005 then 0500, 0501, 0502, 0503, 0504 and 0505, the system remainsin OFF state but if any of the input is $\mathrm{ON}$, those output will be energized one after the other using the timer instruction.

STEP 2: 1000 as latched triggers the timer T000 ON after 50 seconds for the Afikpo power line (0501) to be loaded after synchronization into the micro-grid system. But the normally close contact (T001) will enable only the Afikpo power line alone to be loaded at that particular time.

STEP 3: The timer address T001 become latched thereby energizing the T002 to become ON after 10 seconds for the Amaziri power line (0502) will be loaded after synchronization into the micro-grid system. But the normally close contact (T002) will enable only the Amaziri power line alone to be loaded at that particular time.

STEP 4:The timer address T002 become latched thereby energizing the T003 to become ON after 10 seconds for the Enohia power line (0503) will be loaded after synchronization into the micro-grid system. But the normally close contact (T003) will enable only the Enohia power line alone to be loaded at that particular time.

STEP 5: The timer address T003 become latched thereby energizing the T004 to become ON after 10 seconds for the Ozzia power line (0504) will be loaded after synchronization into the micro-grid system bus. But the normally close contact (T004) will enable only the Ozzia power line alone to be loaded at that particular time.

STEP 6: The timer address T004 become latched thereby energizing the T005 to become ON after 10 seconds for the Uwnana power line (0505) will be loaded after synchronization into the micro-grid system. But the normally close contact (T005) will enable only the Unwana power line alone to be loaded at that particular time. All these actions will be monitoring from the human machine interface and if it requires any alteration, the operator can affect it. If the entire operation 
is to be put on hold, the normally closed contact (T005) will be reenergized by the operator.

The generated powers for the five communities were not loaded into the micro-grid same time because of the following:

i. For easy synchronization of the integrated system

ii. To maintain a stable system which is one of the paramount concepts in Control system

iii. To make the system controllable

iv. The make the system behaviours observable

\section{SUMMARY OF RESULT AND DISCUSSION OF MAJOR FINDINGS}

The major findings in this research reveals that communitybased hybridized renewable system can be monitored and control remotely using PLC and SCADA. The locally available energy resources can be harnessed, power pooled and put to use efficiently, reliably and sustainably when proper energy management scheme is in place. Human Machine Interface has proven its applicability in Renewable energy management as it visibly shown each of the energy sources and its associated contribution in the community level which is a focus of the research. This is because all the standalone, hybridized and optimized renewable energy were wasted without power pool system at the local community level.

\section{CONCLUSION}

This research demonstrates the PLC program capability in monitoring and controlling of a Hybridized community-based power pool system. The monitoring and controlling of this system is achieved through Programmable Logic Controllers (PLC-Kenyence) and the SCADA (intouch) programme. The Supervisory Control \& Data Acquisition system (SCADA) plays the roles of monitoring whereas the PLC plays the roles of controlling the system network. Both the SCADA and the PLC program activities co-ordination via the system behaviour are visibly displayed on the Human Machine Interface (HMI) for the operator to see and further regulate its parameters for efficient, stable and reliable performance. Five communities in Afikpo North Local Government of Ebonyi State (Afikpo town, Amaziri town, Enohia town,Ozzia and Unwana town) were experimentally researched upon. The renewable resources adopted for this research as hybridized were: solar, micro-hydro, wind and biomass energy system. PLC has proven itself as a valuable tool in this study through its ladder logic which facilitates simulation of numerous components and generated load displayable in the HMI and SCADA as designed. The graphs created by SCADA program through its trends make the simulation's results simple, clear and easy to interpret. Voltage generated was $\mathbf{5 K V}$ from Afikpo, Amaziri, Enohia town, Ozzia and Unwana each and were transformed to $11 \mathrm{KV}$. The power generated was rated to be $10 \mathrm{MW}$ with the frequency of $50 \mathrm{~Hz}$. Through the PLC program the generated energy was synchronized into the pool system sequentially. The micro-grid bus energy was controlled and monitored using SCADA and HMI.

\section{REFERENCES}

[1] Brown, C. E. (2002). World Energy Resources. https://doi.org/10.1007/978-3-642-56342-3

[2] Tiwari. (2014). Renewable Energy Sources. Journal of Fundamentals of Renewable Energy and Applications, 4(1), 4541 https://doi.org/10.4172/2090-4541.1000e102

[3] Monforti, F., Huld, T., Bódis, K., Vitali, L., D’Isidoro, M., \& LacalArántegui, R. (2014). Assessing complementarity of wind and solar resources for energy production in Italy. A Monte Carlo approach. Renewable Energy, 63(2014), 576-586. https://doi.org/10.1016/j.renene.2013.10.028

[4] Dawoud, S. M., Lin, X., \& Okba, M. I. (2018). Hybrid renewable microgrid optimization techniques: A review. Renewable and Sustainable Energy Reviews, 82(September 2017), 2039-2052. https://doi.org/10.1016/j.rser.2017.08.007

[5] Yang, B., Yu, T., Shu, H., Zhang, X., Qu, K., \& Jiang, L. (2018). Democratic joint operations algorithm for optimal power extraction of PMSG based wind energy conversion system. Energy Conversion and Management, 159(October 2017), 312-326. https://doi.org/10.1016/j.enconman.2017.12.090

[6] Nuño, E., Maule, P., Hahmann, A., Cutululis, N., Sørensen, P., \& Karagali, I. (2018). Simulation of transcontinental wind and solar PV generation time series. Renewable Energy, 118(2018), 425-436. https://doi.org/10.1016/j.renene.2017.11.039

[7] Makkonen, S. \& Lahdelma (1999). Analysis of Power Pools in the Deregulated Energy Market through simulation.Proceeding of the 23th Hawaic International Conference on System Science (IEEE) 1-9.

[8] Baral, S., \& Kim, K. C. (2014). Existing and Recommended Renewable Energy Conversion Technologies for Electricity Generation in Nepal. Energy and Power, 4(1), 16-28. https://doi.org/10.5923/j.ep.20140401.03

[9] Mohammadi, M., Ghasempour, R., Razi Astaraei, F., Ahmadi, E., Aligholian, A., \& Toopshekan, A. (2018). Optimal planning of renewable energy resource for a residential house considering economic and reliability criteria. International Journal of Electrical Power and Energy Systems, 96(September 2017), 261-273. https://doi.org/10.1016/j.ijepes.2017.10.017

[10]Sansaniwal, S. K., Sharma, V., \& Mathur, J. (2018). Energy and exergy analyses of various typical solar energy applications: A comprehensive review. Renewable and Sustainable Energy Reviews, 82(May 2017), 1576-1601. https://doi.org/10.1016/j.rser.2017.07.003

[11]García-Olivares, A., Solé, J., \& Osychenko, O. (2018). Transportation in a $100 \%$ renewable energy system. Energy Conversion and $\begin{array}{llll}\text { Management, 158(August 2017), } & \text { 266-285. }\end{array}$ https://doi.org/10.1016/j.enconman.2017.12.053

[12]Abhaya Swarup, Mishra P.K. and Swarup P. (1999) 'Energy Management through computer program for modeling PV energy systems', Proceedings of the 23rd National Renewable Energy Convention of the SESI, pp. 151-154.

[13]Martina Calais, Vassilios G. Agelidis and Mike Meinhardt (1999) 'Multilevel converters for single-phase grid connected photovoltaic systems: An overview', Solar Energy, Vol. 66, No. 5, pp. 325-335.

[14]VivekKapil, Fernandez E. and Saini R.P.(1999)'Design of Photovoltaic system for remote areas', Proceedings of the 23rd National Renewable Energy Convention of the SESI, pp. 145-147.

[15]Mohanlal Kolhe, Sunita Kolhe and Joshi J.C. (2002) 'Economic viability of stand-alone solar photovoltaic system in comparison with diesel-powered system for India', Energy Economics, Vol.24, pp.155165.

[16]AydoganOzdamar, HasanYildiz and OzgurSar (2001) 'Wind energy utilization in a house in Izmir, Turkey', International Journal of Energy Research, Vol. 25, pp. 253-261.

[17]Kanat A. Baigarin and Andre de Boer 'Potential of renewable energy resources in Central Asia', A text book on Renewable Energy, pp.7380.

[18]Suresh H., Jangamshetti, and Guruprasada Rau V. (2001) 'Optimum siting of wind turbine generators', IEEE Transactions on Energy Conservation, Vol. 16, pp. 8-13.

[19]Bhave A.G. (1999) 'Hybrid solar-wind domestic power generating system-a case study', Renewable Energy, Vol. 17, pp. 355-358.

[20]Francois Giraud and Zyiad M. Salameh (2001) 'Steady-state performance of a Grid-connected roof top hybrid wind-photovoltaic power system with battery storage', IEEE Transactions of Energy Conversion, Vol. 16, pp. 1-6.

[21]Rajesh Karki and Roy Billinton (2001) Reliability/cost implications of $\mathrm{PV}$ and wind energy utilization in small isolated power systems', IEEE Transactions on Energy Conversion, Vol. 16, No. 4, pp. 368-373. 